\title{
Impact of industry on agricultural development in Sylhet region of Bangladesh: Farmer's perception
}

\author{
Susmita Das Riya*iD \\ Received 27 October 2021, Revised 26 November 2021, Accepted 20 December 2021, Published online 31 December 2021
}

\section{A B S T R A C T}

The study targets at farmer's perception and their cognition how they conceive that agricultural performance has been affected and devastated through industrial work. It reviews and investigates the opinion of $25 \%$ farmers of two villages from each upazila of two named Madhapur and Habiganj sadar upazila in Sylhet division where Charu Ceramic Industry Limited and Olipur industry are located respectively from mid-September to midOctober, 2021 through survey of questionnaire, interview and group discussion. According to $85 \%$ farmers, the industry shades agriculture by imposing an adverse and toxic impact on agricultural exposure and development. Among them, (41.6\% and $48.4 \%)$ of farmers realize that the industry creates high propensity of losing standard quality of soil and water, respectively. They (40.2\%) notice that invasion of several dangerous insects on crops has become prominent and unmanageable near the industrial area. The study represents such kind of realization of farmers to show a salient feature in view of their finding causes and intuition with significant numerical data.

Keywords: Agriculture, Industry, Farmers, Perception, Impact

Faculty of Agriculture, Sylhet Agricultural University, Sylhet, Bangladesh

*Corresponding author's email: susmitariya44@gmail.com (Susmita Das Riya)

Cite this article as: Riya, S.D. 2021. Impact of industry on agricultural development in Sylhet region of Bangladesh: Farmer's perception. Int. J. Agril. Res. Innov. Tech. 11(2): 133-138. https://doi.org/10.3329/ijarit.v11i2.57266

\section{Introduction}

Bangladesh, a country where economy with the process of stepping toward the dreamy objective and destination since its dawn is built based on agriculture. Still now $70 \%$ of population believes that only agriculture is the principle means of obtaining their living source, as they are accustomed to lead their subsistence through it. Agriculture, said the most reliable field to supersede food shortage in Bangladesh, a developing country also it is now stretching the alluring agricultural product and demandable raw substances across the world. Thus makes our economy captivating with foreign currency (Rahman, 2017). Industrialization has placed a part and parcel with its outstanding uprising across the globe including Bangladesh and illustrated a rapid economic progress for a last few decades. According to 2020-21 statistical data, agriculture contributes $13.29 \%$ of GDP and industry shares $30.91 \%$ of GDP (BBS, 2021). However, according to farmers, industry has made a chronic unfavorable fence for developing of agriculture by imposing a negative impact on air, water, soil and climate. The tannery industries utter an imbalance in ecology and create an inhibition from carrying out a healthy ambience for agriculture by involving in soil and water injury (Azom et al., 2012). The participation in movement for saving Sutang river of Habiganj, which loses its viability and efficacy is a visual premise of water injury in front of the residents of selected area.

Sylhet, a northeastern division of Bangladesh in where gas industry, tannery industry, brick kiln industry, rubber industry and industrial park have been developed gradually which is a major concern for the cognizant farmers as they see a scenario of ambience opposite to agriculture. They perceive that the environment is running against agriculture day by day for the lack of proper management and eco-friendly regulation of industrial activity. For carrying metals $\mathrm{Cr}$, the safe management of residuals of leather industry should be imperative instead of disposing wastes directly on covering bare field or public used dustbin hole up and in river, pond and other water bodies (IIou et al., 2012). The direct disposal makes the land sterile gradually and the land tends to lose its propensity of providing nutrients to trees. Although coal-mining industry has made us allured with a good qualified coal, it has ruined the weather and environment chronologically with the trait of injurious to 
natural resources (Hossain et al., 2019). Industry has reared the moving toward a desirable economy and empowerment but it has become a cursed threat to our nature. Brick kiln industry, which is developed swiftly in Bangladesh acts as a prime factor in the activity of putting crops in environmental stress in shortage of fresh air caused by emission of sulfur dioxide, carbon dioxide, carbon monoxide and assists in growing up of temperature (Skinder et al., 2013). The function involved in petroleum resources extraction in gas and oil industry clashes with environment and causes atmosphere impurity, biodiversity loss and also land, forest and water resources depletion (Emoyan et al., 2008). An noticeable extent of pollutants including sludge, hazardous organic compounds ammonia, risky hydrogen sulphide, venturesome chemicals such as chromium, synthetic tannins, insalubrious oil are released from leather industry which defiles soil, water and thus creates an intense liability of amplifying environment friendly greener technology operative to regain the agricultural environ (Sumita et al., 2015). Land loses soil nutrients and gains acidity as being abused with intolerable heavy metals near the brick kiln industry and soil degradation and profanity provide an ominous fence for agriculture. (Bisht and Neupane, 2015). In Bangladesh, brick kiln industry rears a negative impact on ecology and Arsenic, Cadmium that are major available including secondary availability of Nickel, Chromium and Lead exist in the area near the industry contaminate the environment (Proshad et al., 2017). In addition, near the brick kiln area, the plants lose natural food forming process named photosynthesis, are not able to carry out its growth and development and cannot possess its usual fruit shape, height (Adrees et al., 2016). The top soil of land having heavy metals near the brick industry is in a dangerous state and thus affects agricultural productivity as soil is the first demand for growing up of plants (Shaha et al., 2021). According to the residents of selected area in Sylhet, the farmers also sell their top soil of land to the industry authority for a temporary benefit, which is used in industrial work and make their land unsuitable for plant growth. In addition, the underground land near the brick kiln industry loses its viability and existing lives are reduced to death (Gupta and Narayan, 2010). Several studies have been represented based on industrial impact but there was no one based on farmer's perception. The main objective of the study to evaluate the impact of industry on agriculture in the farmer's eye. The study demonstrates the perception and observation of farmers of Sylhet about the impact of industry on agricultural ambience and natural resources related to agriculture.

\section{Methodology}

\section{Site selection}

To explore the impact of industry on agriculture, two upazilas of Habiganj district situated in north-eastern region of Bangladesh in Sylhet Division named Madhabpur and Habiganj Sadar were selected. Two villages of each upazila were picked out based on geographical location based on availability of industry and opinion of Upazila Agriculture Officer (UAO) and Sub-Assistant Agriculture Officer (SAAO).

\section{Data collection}

To accumulate the data for analysis of the study, three kinds of methods, which are effective and popular for collecting appropriate information were used from mid-September to mid-October 2021. First of all, with the help of SAAO, Chairman, Member, Sordar of villages and representatives of respective upazila, a list of 400 of total 1600 farmers of selected two villages of each selected upazila which was $25 \%$ of total farmers of specific area was made to perform a primary survey through questionnaire about their age, education, family size, farm size, farming experience, other profession besides farming, their positive and negative attitude towards industry and agriculture based on their empowerment, income and surrounding environment and the extent of several changes of environment they invent after construction of industry.

Afterwards, an interview session was conducted with them to pull out their opinion apparently. Then the selected samples were sub divided into 10 groups for having group discussion to gather their collective opinion. Finally, an ultimate general discussion was extended for a couple of days.

\section{Data analysis}

The data through SPSS software into numerical number and tabulated form were analyzed and coded. To make the study apprehensible, two statistical measures such as percentage, range were used along with writing in text.

\section{Results and Discussion}

\section{Socio-economic characteristics of the participated farmers}

Based on socio-economic aspects, the participated farmers were arranged in category in this regard. Most of the farmers (42.5\%) who revealed their cognition in the survey of questionnaire belonged to $18-35$ years demonstrated on the table 1 where majority of the farmers could sign properly and $36.6 \%$ crossed primary school education. In case of family, majority (39.3\%) had large sized family and majority (44.2\%) had high farming experience since their childhood where (40.8\%) of them had medium farming experience. Only 38.0\% involved other profession besides cultivating such as student, fishing, boatman and carpenter. 
Table 1. Socio-economic characteristics of farmers.

\begin{tabular}{|c|c|c|}
\hline \multicolumn{3}{|l|}{ Age Percentage } \\
\hline Young aged (18-35) & Middle aged (36-46) & Old aged (above 46) \\
\hline $42.5 \%$ & $39.7 \%$ & $17.8 \%$ \\
\hline \multicolumn{3}{|c|}{ Educational Level Percentage } \\
\hline \multicolumn{2}{|c|}{ No Education } & $22.5 \%$ \\
\hline \multicolumn{2}{|c|}{ Primary Education (1-5) } & $36.6 \%$ \\
\hline \multicolumn{2}{|c|}{ Secondary Education (6-10) } & $32.9 \%$ \\
\hline \multicolumn{2}{|c|}{ Higher Secondary Education (11-12) } & $2.0 \%$ \\
\hline \multicolumn{2}{|c|}{ Higher Education (13 \& above) } & $6.0 \%$ \\
\hline \multicolumn{3}{|c|}{ Family Size Percentage } \\
\hline Small (2-4) & Middle (5-7) & Large (8 \& above 8$)$ \\
\hline $25.2 \%$ & $35.5 \%$ & $39.3 \%$ \\
\hline \multicolumn{3}{|c|}{ Farm Size Percentage (Hectare) } \\
\hline Small (0.20-1.00) & Medium (1.10-2.99) & Large (3.0 \& above 3) \\
\hline $47.5 \%$ & $40.7 \%$ & $11.8 \%$ \\
\hline \multicolumn{3}{|c|}{ Farming Experience Percentage } \\
\hline Low & Medium & High \\
\hline $15.0 \%$ & $40.8 \%$ & $44.2 \%$ \\
\hline \multicolumn{3}{|c|}{ Other Profession Besides Cultivating } \\
\hline \multicolumn{2}{|c|}{ Yes } & No \\
\hline \multicolumn{2}{|l|}{$38.0 \%$} & $62.0 \%$ \\
\hline
\end{tabular}

Finding of a general perception of air, soil and water. They (47.4\% and $34.9 \%$ ) farmers about the impact of industry on thought the impact was both medium and high, environment taking place

Majority (85.0\%) of participated farmers elicited a negative impact occurred after construction of respectively. We had only focused on the opinion of the majority $(85.0 \%)$ to continue the study comprehensible. industry on elements of environment including

Table 2. A general perception of farmers about the impact of industry.

\begin{tabular}{|c|c|c|}
\hline \multicolumn{3}{|c|}{ Perception about the impact on environment } \\
\hline Positive impact & Negative Impact & No impact \\
\hline No percentage & $85.0 \%$ & $15.0 \%$ \\
\hline \multicolumn{3}{|c|}{ Perception about intensity of negative impact on environment } \\
\hline Low & Medium & High \\
\hline $17.7 \%$ & $47.4 \%$ & $34.9 \%$ \\
\hline
\end{tabular}

Finding of perception of farmers about observed medium impact, respectively but about the industrial impact on air, soil and the impact on water, majority (48.4\%) perceived water high change. It seems that air, soil and water in river or pond of an industrial area are toxic and The opinion revealed by the farmers about river or pond of anhealthy for utilization to all lives in comparison impact on air, soil and water was negative and with a non-industrial area (Ogedengbe and Oke, disappointing. In case of impact on air and soil, majority (46.2\% and 42.0\%) agreed and they 2011).

Table 3. Perception of farmers about the impact on air, soil and water

\begin{tabular}{|lcc|}
\hline \multicolumn{4}{|c|}{ Pew } & Medium & High \\
$11.7 \%$ & $46.2 \%$ & $42.1 \%$ \\
\hline Low & Perception about the impact on soil & High \\
$16.4 \%$ & Medium & $41.6 \%$ \\
\hline & $42.0 \%$ & High \\
Low & Perception about the impact on water & $48.4 \%$ \\
\hline
\end{tabular}


Finding of perception of farmers about the causes of industrial impact on air, soil and water

Majority (67.4\%) of the farmers narrated that the incessant gas produced from the industry had contaminated the fresh air, which was visible in naked eyes. Several risky gases produced from the brick kiln industry simultaneously cause air polluted and poor quality, which affects agricultural crops (Hoang and Nguyen, 2010). Some (12.4\%) of them found no reason and their perception about the fact was a natural process. In case of soil, majority (45.7\%) perceived that the cultivated land had reduced in quantity and lost its nutritional quality. Also $36.2 \%$ of them thought about the reason of reduction of soil quality that top soil was used in industrial work for ceramic forming activities, as it was visible to them. The losing of top soil, which is the prime element for crops growth, can cause nonproduction and shortage of food (Hossain et al., 2019). Some (10.6\%) of them thought the extent of heavy metals in soil had gradually increased. The remaining others took it as a natural process. In regard of water, they asked us to visit Sutang River so that we could fathom the reflection of industrial impact on river. They perceived that the river had died, lost its natural depth and color, being cursed with black, sour and fault water also the lives of river subjected to death. They made the industry liable for this. More than one-third (44.1\%) farmers felt disposal of industrial waste in river pollute the water. In case of leather industry, chromium level is minimized for protection of environment and reduction of toxicity by repeated using of wastewater (Patrice et al., 2019).

Table 4. Perception about the causes of impact on air, soil and water.

\begin{tabular}{|c|c|}
\hline \multicolumn{2}{|l|}{ Perception about the causes of impact on air } \\
\hline No cause & $12.4 \%$ \\
\hline Production of gas from industry & $67.4 \%$ \\
\hline Other accessory technologies, vehicles & $20.2 \%$ \\
\hline \multicolumn{2}{|l|}{ Perception about the causes of impact on soil } \\
\hline No cause & $7.5 \%$ \\
\hline Reduction in quantity & $45.7 \%$ \\
\hline Selling of top soil to industrial authority & $36.2 \%$ \\
\hline Mixing up with heavy metal & $10.6 \%$ \\
\hline \multicolumn{2}{|c|}{ Perception about the causes of impact on water } \\
\hline No cause & $9.2 \%$ \\
\hline Used in industrial work & $46.7 \%$ \\
\hline Disposal of waste of industry & $44.1 \%$ \\
\hline
\end{tabular}

Finding of perception of farmers about the impact of industry on temperature, rainfall

perceived that temperature became lower in winter and $16.9 \%$ of them found no reason. In case of rainfall, majority $(43.7 \%)$ revealed that they felt reduction in rainfall and $37.5 \%$ of them felt untimely rainfall.

Majority $(52.7 \%)$ of the farmers felt temperature crossed its natural level during summer and a countable number (30.4\%)

Table 5. Perception of farmers about the impact on temperature and rainfall.

\begin{tabular}{|c|c|}
\hline No impact & $16.0 \%$ \\
\hline Increased temperature in summer or drought & $52.7 \%$ \\
\hline Decreased temperature in winter or coldness & $30.4 \%$ \\
\hline \multicolumn{2}{|l|}{ Perception about the impact on rainfall } \\
\hline No impact & $10.2 \%$ \\
\hline Reduction in rainfall & $43.7 \%$ \\
\hline Unusual rainfall in respect of time & $37.5 \%$ \\
\hline Rainfall more than normal or excess & $8.6 \%$ \\
\hline
\end{tabular}

Finding of perception of farmers about the causes of impact of industry on temperature, rainfall

The majority (45.8\%) of farmers thought that the land quantity reduced after industry had built up; that's why deforestation and cut down of numerous aged plants for building up new residences for growing up population taking place with the development of industry. Such activities aid to continue to speed up temperature in a curse manner. The trees have a comfortable optimum temperature range to continue their development function. The gradual speed up of temperature deviates them from continuing their 
natural physiological process. By perceiving that, the farmers were in anxiety and felt unsafe for their desirable crops. They also made the industry responsible for the unethical act of producing gas continuously. In case of automotive industry, Magnesium can be used in a wide way to save the ambience from toxic high temperature as temperature increases in a swift speed in the industry production process
(Mustafa, 2008). In the farmer's thought deforestation also led to an unusual nature in rainfall. They expressed the significant feature of rainfall for grain flourishment and welldeveloped traits of plant but they felt a difference in plant growth for shortage or excessive nature of rainfall.

Table 6. Perception of farmers about the causes of impact of industry on temperature, rainfall.

\section{No cause}

Deforestation after construction of industry

Gas production from industry

\section{$14.4 \%$ \\ $45.8 \%$ \\ $39.8 \%$}

\section{Finding of perception of farmers about the impact of industry on plant development}

Almost more than one-third (40.2\%) found rapid availability of insects which acted as a barrier in plant growth. They tried to excess the dose of insecticide from recommended one day by day, which made the insects gradually resistant to the insecticide. They also observed reduced plant height near the industrial area and dying of plants in dryness. The plants deflect from normal morphological or external appearance in case of exceeding heavy metal and wastewater has a leaning to minimize and deter growth of seedlings of a major crop called prime food of us is rice (Katepogu et al., 2015).

Table 7. Perception of farmers about the impact on plant development.

\begin{tabular}{|ll|} 
Reduction in plant height & $11.2 \%$ \\
Intensity of insects & $40.2 \%$ \\
Retarded growth & $15.7 \%$ \\
Reduction in yield & $20.1 \%$ \\
Drying and dying of plants & $12.8 \%$ \\
\hline
\end{tabular}

Finding of perception of farmers about their positive and negative attitude towards industry and agriculture based on empowerment, income and interest

More than one third of the participated farmers (40.6\%) perceived that they could income easily by involved in industry. They thought it would take less time as they got the wage daily being a worker and there was no risk of losing yield victimized by extreme weather impact. In addition, there was no sharing of profit with the owner of the land. On the other hand (59.4\%) of the farmers adored cultivating as they were involved since their childhood and they enjoyed the rice, vegetables cultivated with their own hand. They even could not think that they would quit farming as their ancestor also served the same occupation. They also did not face safe as they heard working in the industry caused health insalubrious. However, all of the participated farmers agreed that they wanted industry in this area as they thought industry meant development but they were also in agony, as they perceived gradually that the industry was making the environment unfavorable for natural lives. They demanded an eco-friendly industry so that industry and agriculture could not clash. They did not want to imagine the scenario of shortage of paddy in their residence by making the agricultural ambience unfavorable. The favorable measures, use of fertile soil in an auspicious weather, a great effort of extension worker and proper management can provide food availability firm for all in a developing country like us (Pawlak and Kolodziejczak, 2020).

\section{Conclusion}

The farmer's perception seems sound as they are habituated to the environment and have enough intuition to catch up the change. They access that the compulsory requirements such as soil and water for agricultural development are being degraded and also temperature, rainfall which are momentous for crop enhancement have turned into adverse form for plant growth. They have also explicated that insect intensity has crossed its natural level and an intolerable use of insecticide has made the surroundings including soil, water and the product unsuitable and unhygienic. In fact, they have felt that the plants initiate to lose its natural growth tendency and production ability.

Industry is essential in Bangladesh to overcome unemployment problem and for being consistent to run with the worldwide development. However, putting agricultural development in a dangerous state to continue the industry is an 
irreplaceable damage, which we will not be able to make up in future. The farmers are realizing that the industrial activities create imbalance with the agricultural activities and they will suffer a fixed loss of propitious surroundings for agriculture in future if the situation is running on. They demand an industry with a systemic disposal system, eco-friendly management, nondependable on natural resources and nonopposite to agricultural ambience. Almost 85.0\% of farmer's view explicates how the environment is being dominated and its natural stream is lost after construction of industry. They also perceive that it is a slight impact and the natural resources will be devastated gradually unless the respective authority and policymaker take considerable rules and set up them as soon as possible. The study narrates the alteration perceived by the farmers for building up industry in the area, assists the investigators to further study and facilitates the policymaker to figure out the inhibition and puzzle faced by the farmers.

\section{References}

Adrees, M., Ibrahim, M., Shah, A.M., Abbas, F., Saleem, F., Rizwan, M., Hina, S., Jabeen, F. and Ali, S. 2016. Gaseous pollutants from brick kiln industry decreased the growth, photosynthesis and yield of wheat (Triticum aestivum L.). Environ. Monit. Assess. 188: 267. https://doi.org/10.1007/s10661-016-5273-8

Azom, M.R., Mahmud, K., Yahya, S.M., Sontu, A. and Himon, S.B. 2012. Environmental Impact Assessment of Tanneries: A Case Study of Hazaribag in Bangladesh. Int. J. Environ. Sci. Dev. 3(2): 152-156. https://doi.org/10.7763/IJESD.2012.V3.206

BBS. 2021. Gross Domestic Product (GDP) 20202021. Bangladesh Bureau of Statistics. p. 2.

Bisht, G. and Neupane, S. 2015. Impact of brick kilns' emission on soil quality of agriculture fields in the vicinity of selected Bhaktapur area of Nepal. Appl. Environ. Soil Sci. Article ID 409401, 8.

https://doi.org/10.1155/2015/409401

Emoyan, O.O., Akpoborie, I.A. and Akporhonor, E.E. 2008. The Oil and Gas Industry and the Niger Delta: Implications for the Environment. J. Appl. Sci. Environ. Manage. 12(3): 29-37.

https://doi.org/10.4314/jasem.v12i3.55488

Gupta, S. and Narayan, R. 2010. Brick kiln industry in long-term impacts biomass and diversity structure of plant communities. Curr. Sci. 99(1): 1-7.

Hoang, A.L. and Nguyen, T.K.O. 2010. Integrated assessment of brick kiln emission impacts on air quality. Environ. Monit. Assess. 171: 381-394.
Hossain, M.A., Zahid, A.M., Arifunnahar, M. and Siddique, M.N.A. 2019. Effect of brick kiln on arable land degradation, environmental pollution and consequences on livelihood of Bangladesh. J. Sci. Tech. Environ. Inform. 6(2): 474-488.

https://doi.org/10.18801/jstei.060219.50

IIou, I., Souabi, S. and Digua, K. 2012. Quantification of pollution discharges from tannery wastewater and pollution reduction by pre-treatment station. Int. J. Sci. Res. 3(5): 1706-1715

Katepogu R., Vishnubardhan, V. and Damodharam, T. 2015. Industrial effluent of seedling growth of rice and wheat (Oryza sativa L. and Triticum vulgare L.). Int. J. Recent Sci. Res. 6(7): 4935-493.

Mustafa, K.K. 2008. Magnesium and its alloys applications in automotive industry. Int. $J$. Adv. Manufac. Tech. 39(9-10): 851-865. https://doi.org/10.1007/s00170-007-1279-2

Ogedengbe, K. and Oke, A.O. 2011. Pollution impact of cement production on air, soil and water in a production location in Nigeria. $J$. Sci. Tech. 31(2): 46-56. https://doi.org/10.4314/just.v31i2.69393

Patrice, M. de A., Hansen, E. and Gutterres, M. 2019. Water reuse: An alternative to minimize the environmental impact on the leather industry. J. Environ. Manage. 230: 456-463.

https://doi.org/10.1016/j.jenvman.2018.09.077

Pawlak, K. and Kolodziejczak, M. 2020. The role of agriculture in ensuring food security in developing countries: Considerations in the context of the problem of sustainable food production. Sustain. 12(13): 5488. https://doi.org/10.3390/su12135488

Proshad, R., Ahmed, S., Rahman, M. and Kumar, T. 2017. Apportionment of hazardous elements in agricultural soils around the vicinity of brick kiln in Bangladesh. $J$. Environ. Anal. Toxicol. 7(439): 1-7. https://doi.org/10.4172/2161-0525.1000439

Rahman, M.T. 2017. Role of Agriculture in Bangladesh Economy: Uncovering the Problems and Challenges. Int. J. Busi. Manage. Inven. 6(7): 36-46.

Saha. M.K., Sarkar, R.R., Ahmed, S.J., Sheikh, A.H. and Mostofa, M.G. 2021.Impact of brick kiln emission on agricultural soil around brick kiln areas. Nepal J. Environ. Sci. 9(1): 01-10. https://doi.org/10.3126/njes.v9i1.34918

Skinder, B.M., Sheikh, A.Q., Pandit, A.K. and Ganai, B.A. 2014. Brick kiln emissions and its environmental impact: A Review. J. Ecol. Nat. Environ. 6(1): 1-11. https://doi.org/10.5897/JENE2013.0423

Sumita, D., Yadav, A., Dwivedi, P.D. and Das, M. 2015. Toxic hazards of leather industry and technologies to combat threat: a review. $J$. Cleaner Prod. 87: 39-49.

https://doi.org/10.1016/j.jclepro.2014.10.017 